to return to Sir Raymond Hoffenberg, who puts forward some of the problems of the Third World, and explains how over the next ten years, if nothing new is done, we shall see 25 million deaths from measles, and four million cases of parolytic poliomyelitis. He reminds us, in a sobering conclusion to his essay that the six WHO killer scourges of the Third World - diptheria, measles, poliomyelitis, tetanus, TB and whooping cough - could all be eliminated if we diverted annually to their eradication what we spend on armaments every three hours.

I would have liked to have seen more on the Third World and felt that this could have been covered more fully. It is a shame that such a chapter was not included, perhaps at the expense of the one on information and medical journals, which was very dry.

PHILIP STEADMAN MSc MBBS DIC, House Surgeon, Guy's Hospital, London SE 1

\section{AIDS: Professional Secrecy}

Edited by Paolo Cattorini, xvi +71 , Padua, Italy, price unavailable, Liviana Editrice, 1989

This book is a collection of essays, written by authors with different qualifications and expertise (medical, legal and theological) and dealing with the attitude that health-care professionals should take towards the AIDS patient.

The authors examine the problem starting from a specific point of view consisting of the following premises: on the one hand there is the duty of doctors and other health-care professionals to keep secret that which they come to know in the exercise of their profession; on the other hand there is a need to protect society from infection and a need to protect patients from the hysterical and disproportionate reactions caused by this particular disease.

M Cuyas sj tries to balance these contrasting issues by stressing the importance of the duty of secrecy. According to him, this duty is a consequence of the individual's right to privacy. Even though Cuyas gives a strong foundation to the secrecy requirement he thinks that in certain circumstances, for example in the case of AIDS infection, it can be overridden by other requirements.

H E Emson explains the 'descending parabola' of the professional secret and asserts that it has been more and more exhausted. He takes an example from English common law in order to show that it permits several cases of infringement of secrecy in order to protect the common interest. Thus, he concludes, the duty to secrecy is only a conditional duty. According to Emson in the case of AIDS the infringement of the professional secret is related not only (as other authors assert) to the safety of the partner, but also to the safety of healthcare professionals in hospitals.

M Kottow's position is absolutely contrary to that of Emson. He says that doctors have an absolute duty to maintain secrecy. This duty is absolute not 'as such' but as a matter of history, since it is necessary to the patientdoctor relationship. Other people who are not doctors, are in charge of the safety of innocent third persons.

C Lega tries to find an answer to the dilemma by resorting to medical deontology and its principles. He asserts a principle of concealment, which admits some exceptions in certain circumstances, specified by Italian criminal law. Lega thinks that AIDS constitutes another justified exception, since society must protect third parties who live with sick persons.

A Farneti, as well as Lega, holds that doctors have a stronger duty to prevent the risk that other people are infected by a sick person who does not tell those other people about his condition.

L Tornotti does not stress the problem of communicating the risk to a relative or to a partner. She underlines the problem of patient privacy in the bureaucratic processes, as in the case of social insurance. This loss of privacy is injurious for the sick person and of no value to society.

Cattorini concludes by considering the question of communication to the cohabiting partner. He remarks that from an ethical point of view we must take into account both the consequences of a single act and those of a rule envisaged as a condition of greater benefit. This appears to be like ruleutilitarian reasoning, but it is not. It is a consideration developed in the framework of a teleological model, in which the end (and Cattorini quotes Sgreccia) is the achievement of fundamental values according to Catholic teaching.

The conclusion of the reasoning is the assertion of a principle of concealment as a value having the right to priority but only prima facie. This principle can be infringed when it conflicts with other duties.

The issues discussed in the book are therefore the following: the respect towards the patient seen as a person in his value, in his essence and eventually in his privacy; the value of the patientdoctor relationship founded on reciprocal trust; the conflicts between individual rights and community interests; the question of the equilibrium between the respect of the person from the point of view of the tradition of the personalistic anthropology (the tradition that authors adopt in the first part of the book) and the danger for society.

The global answer to this question is that when there is excessive danger for society, respect for the sick person (ie the requirement to keep his disease secret) can be infringed.

The authors therefore recognise two prima facie duties, but they do not succeed in giving a clear hierarchy between these duties. In fact the reasoning of authors who recognise a priority, such as Kottow or Emson (who recognise the absolute value of professional secrecy or its relativity, respectively) are out of step with the rest of the text and they are diluted in Cattorini's introduction.

The book, after all, is more a collection of questions than of answers. The right questions are posed even if this is done by using only a specifically ethical approach that invalidates the universal value of the questions.

CATERINA BOTTI, Department of Philosophical and Epistemological Studies, University of Rome, 'la Sapienza', Via Nomentana 118, 00161, Rome 